\title{
Analysis on the Optimization of Midea Group's Capital Structure
}

\section{Xuefei Zhang}

\author{
School of Economics and Management, Beijing Jiaotong University, Beijing, China
}

19120682@bjtu.edu.cn

Xuefei Zhang

Keywords: Midea Group, Capital Structure, Optimization.

\begin{abstract}
The optimization and improvement of the capital structure is closely related to the value of the company. Capital not only has a critical impact on the current production and operation of enterprises, but also is an indispensable resource in the development of modern enterprises, especially in the financing process of enterprises. Based on the financial report of Midea Group, this paper firstly draws the current status of the capital structure of Midea Group. Then use the optimal capital structure quantitative model proposed by Professor Jianbo Meng and Professor Lin Luo of Jinan University to statically calculate the optimal capital structure of Midea Group. Finally, some practical optimization measures for the capital structure of Midea Group are proposed.
\end{abstract}

\section{浅析美的集团资本结构优化研究}

\author{
张雪飞 \\ 北京交通大学经济管理学院, 北京, 中国 \\ 19120682@bjtu.edu.cn \\ 张雪飞
}

关键词：美的集团；资本结构；优化

中文摘要. 资本结构的优化和改进与企业价值息息相关。资本不仅对当前企业的生产和经营 有着不可忽视的影响, 而且是现代企业发展过程中不可或缺的资源, 尤其在企业的融资过程 中扮演着重要角色。本文首先根据美的集团的财务报告, 得出美的集团的资本结构现状, 然 后利用暨南大学孟建波和罗林教授提出的最优资本结构定量模型静态测算出美的集团最优 资本结构，最后对美的集团资本结构提出一些切实可行的优化措施。

\section{1. 引言}

在供给侧改革以及消费升级的带动下中国的经济形势虽然整体上出现了较高的增速，但 不容乐观的是, 在新形势下家电行业的市场逐渐趋于饱和, 这对于家电行业来说, 机遇与挑 战并存。企业需要不断吸收更多的资本来壮大自己的实力, 这也就面临着如何选择和安排债 务资本和权益资本才能实现企业价值最大化的问题。因此企业在做筹资决策时应把资本结构 优化作为决策的核心。

\section{2. 资本结构相关理论概述}

资本结构是企业各种资金来源的构成以及它们之间的比例关系。资本结构的概念分狭义 和广义两类：狭义的观点认为资本结构是企业各种长期资本的构成和比例关系; 广义的观点 
认为资本结构是企业全部资本的构成及其比例关系。基于美的集团资本结构现状，本文采用 广义的概念进行论述。与资本结构相关的理论主要包括MM理论、融资优序理论、信号传递 理论、代理成本理论等。资本结构相关理论为企业提供了最优资本结构的说明, 以MM理论 为基础并结合数学、统计、计量经济学等出现了资本结构静态优化的方法。

\section{3. 美的集团资本结构现状}

本文通过对美的集团2014年至2018年的财务报告进行整理和分析，得出美的集团的总资 本结构现状、债务资本结构现状、权益资本现状和融资偏好现状。

\section{1 总资本结构现状}

根据表1可得，2014年至2018年美的集团的产权比率大体在150\%左右，表明美的集团的 债务资本大概是权益资本的 1.5 倍。从行业均值来看, 产权比率基本保持在 $90 \%$ 左右。通过比 较后发现，2014年至2018年美的集团产权比率均高于行业均值, 表明相对于股权资本来说, 美的集团的债务资本要高于行业债务资本的平均水平。

表1 产权比率

\begin{tabular}{|c|c|c|c|c|c|}
\hline & 2014 年 & 2015 年 & 2016 年 & 2017 年 & 2018 年 \\
\hline 美的集团 & $159.98 \%$ & $128.67 \%$ & $132.56 \%$ & $183.39 \%$ & $185.23 \%$ \\
\hline 行业均值 & $83.33 \%$ & $77.14 \%$ & $85.52 \%$ & $93.40 \%$ & $107.10 \%$ \\
\hline
\end{tabular}

\section{2 债务资本结构现状}

根据表2可得，2014年至2018年美的集团的资产负债率大体保持在60\%，前四年整个家电 行业基本稳定在 $31 \%$ 左右, 2018年略有升高。通过比较发现, 美的集团的资产负债率高于行 业均值, 这表明美的集团的负债水平在整个行业内是相对较高的, 因此面临的财务风险也较 大。

表2 资产负债率

\begin{tabular}{|c|c|c|c|c|c|}
\hline & 2014 年 & 2015 年 & 2016 年 & 2017 年 & 2018 年 \\
\hline 美的集团 & $61.98 \%$ & $56.51 \%$ & $59.57 \%$ & $66.58 \%$ & $64.94 \%$ \\
\hline 行业均值 & $32.47 \%$ & $30.38 \%$ & $31.17 \%$ & $31.17 \%$ & $45.17 \%$ \\
\hline
\end{tabular}

根据表 3 可得, 美的集团的流动负债占比较高。一般来说, 一个企业最适合的流动负债占 比为 $50 \%$ 左右。美的集团的短期负债过多，长期负债过少。短期负债需要在一年或一个营业 周期内偿还，一旦企业自身的资金链断裂将会对企业的经营带来较大的风险。

表3 美的集团负债结构

\begin{tabular}{|c|c|c|c|c|c|}
\hline & 2014 年 & 2015年 & 2016 年 & 2017 年 & 2018 年 \\
\hline 流动负债/总负债 & $98.10 \%$ & $98.89 \%$ & $87.76 \%$ & $72.10 \%$ & $76.05 \%$ \\
\hline 非流动负债/总负债 & $1.90 \%$ & $1.11 \%$ & $12.24 \%$ & $27.90 \%$ & $23.95 \%$ \\
\hline
\end{tabular}

\section{3 权益资本现状}

美的集团于2013年9月18日在深圳证券交易所上市，截止日期到2019年3月31日美的集团 的股东持股情况如表4所示, 美的集团的第一大股东美的控股有限公司的持股数量达到了 2212046613股, 持股比例达到了 33.54\%, 与其他三大股东相比持股比例较多。但是第一大股 东百分之三十多的持股比例在家电行业里来说，股权还是相对比较分散的。 
表4＼cjkstart截至2019年3月31日前四大股东持股情况

\begin{tabular}{|c|c|c|}
\hline 持股股东 & 持股数量（股） & 持股比例（\%) \\
\hline 美的控股有限公司 & 2212046613 & 33.54 \\
\hline 香港中央结算有限公司 & 1069044139 & 16.21 \\
\hline 中国证券金融股份有限公司 & 198145134 & 3.00 \\
\hline 方洪波 & 136990492 & 2.07 \\
\hline
\end{tabular}

\section{4 融资偏好现状}

根据表5可得, 2014年至2018年美的集团的内部可融资金额最多，意味着留存收益逐年增 加, 表明美的集团未能充分利用内部融资。比较两种外源性融资, 2014年至2016年股权融资 的金额比债权融资多。2014年至2018年的五年内股权性融资金额基本保持稳定小幅度增长; 2017年债权性融资上涨幅度较大，增加的金额达300多亿，通过查报表知道原因在于长期借款 中有约 290 亿元的抵押借款, 但这并不是美的集团经常发生的业务。综上所述, 美的集团偏好 于股权性融资。

表5 美的集团融资情况

单位: 亿元

\begin{tabular}{|c|c|c|c|c|c|}
\hline & 2014年 & 2015年 & 2016年 & 2017年 & 2018年 \\
\hline 内部可融资 & 230.04 & 313.77 & 409.09 & 515.09 & 638.41 \\
\hline 股权融资 & 172.41 & 187.78 & 200.56 & 224.73 & 251.14 \\
\hline 债权融资 & 62.43 & 40.11 & 100.96 & 401.23 & 329.61 \\
\hline
\end{tabular}

\section{4. 美的集团资本结构优化模型}

首先需要选择适合美的集团资本结构的决策方法。资本结构决策方法主要有三种：资本 成本比较法、每股收益分析法、公司价值比较法。本文在美的集团以价值最大化为目标时对 应的资产负债率作为资本结构优化的结果。本文采用孟建波和罗林教授提出的最优资本结构 定量模型对美的集团的资本结构进行静态测算, 得出一个最优的资产负债率。具体公式为:

$$
\operatorname{Ln}(V r-I)=(F+I) /(V r-I)+(V r+F) / V * 100 b /(1-b)
$$

式中(Vr-I)表示利税前收益减去利息支出，即税前利润总额E；F表示固定成本；I表示利 息费用; V表示企业的总资产; $b$ 表示企业的最优负债率。

建立模型时，用财务报表中的财务费用代替公式中的利息费用I；用固定资产的折旧费用 $\mathrm{Z}$ 和长期债务利息iL的和代替固定成本F，因此进行测算的方程式为:

$$
L \mathrm{n} E=(Z+i L+I)+(E+I+Z+i L) / V * 100 b /(1-b)
$$

根据2018年美的集团财务报告，公司利润总额E为25773058000，折旧费用Z为3362075000， 利息支出 $I$ 为 1823040000 , 总资产 $\mathrm{V}$ 为 263701148000 , 长期借款利息iL为946697451。将数据 代入公式(2)中得出 $b=69.02 \%$, 即 2018 年的最优负债率为 $69.2 \%$ 。

同理，根据相关财务数据可求得美的集团在 2014 年的最优负债率为 $62.69 \% ， 2015$ 年的最 优负债率为 $62.04 \% ， 2016$ 年的最优负债率为 $65.82 \% ， 2017$ 年的最优负债率为 $68.37 \%$ 。若用负 债率来表示企业的资本结构, 那么上述最优负债率b即为美的集团各年的最佳资本结构。结合 表1美的集团的资产负债率可知，2014年至2018年美的集团最佳资本结构的负债率都高于实 际资本结构下的负债率, 说明美的集团2018年没有达到最佳资本结构不是偶然, 而是长期以 来都存在债务资本相对偏低的情况, 所以美的集团应根据测算出的最佳资本结构并结合自身 实际情况适当提高债务资本的比例。 


\section{5. 美的集团资本结构优化措施}

\section{1 调整总资本结构}

在分析了美的集团资本结构现状后得出, 在总资本结构方面, 美的集团的债务资本相对 于股权资本来说高于行业平均水平。但是美的集团作为家电行业的龙头企业, 在偿债能力和 资信能力方面，理应高于行业的其他企业，因此债务资本可以相对偏多一些。

\section{2 调整债务资本内部结构}

企业的总体负债需要控制在合理的区间内, 合理的负债结构可以降低财务风险, 减少还 款压力, 实现企业价值最大化。除此之外, 还要考虑负债内部结构的合理。

\subsection{1 平衡长短期负债}

通过对美的集团的债务资本内部结构现状进行分析得出, 债务资本中非流动负债占总负 债的比例相对较小、流动负债占比较大。因此可通过平衡流动负债和非流动负债来优化美的 集团的资本结构，应当根据企业的实际情况适当增加长期负债。

\section{2 .2 构建企业多元融资体系}

根据对美的集团的融资偏好现状进行分析可知，美的集团偏好于股权融资，这也是我国 上市公司普遍存在的问题。这一问题的根源在于我国的债券市场发展还很不完善, 对于企业 发行债券的限制条件较多而且十分严格, 使得企业发行债券的程序繁琐、复杂、耗时耗力, 而且债券筹资有一定额度的限制, 累计总额发行不得超过公司净资产的 $40 \%$, 而发行股票相 对于发行债券而言, 限制条件少。美的集团的债券发行少, 美的集团是家电行业的领头羊, 发行债券的能力较强, 因此应提高债权融资比例。这样做不仅对企业自身有利, 对于债券市 场的发展也会一定的贡献。

综上所述，企业在选择融资方式时应权衡各融资方式的风险与收益，再结合企业的最佳 资本结构构建出多元化并可平衡各融资方式的融资体系。美的集团目前的融资方式是以股权 融资和流动负债为主，因此美的集团应该根据测算出的最佳资本结构构建出以内源融资为主、 负债和债券融资为辅且平衡流动负债和非流动负债的多元化融资体系。

\section{References}

[1] Chunsheng Yuan and Jinru Guo, Study on the Impact of Monetary Policy Changes on the Dynamic Adjustment of Enterprise Capital Structure-Evidence from Chinese Public Companies, Macroeconomic Research, vol.07, pp. 19-32, 2018.

[2] Jing Li, Analysis on the Structure Optimization of Capital of Public Companies, Modern Commerce, vol.18, pp. 67-68, 2017.

[3] Lihua zhang, Research on Capital Structure Optimization of Real Estate Industry, China Market, vol.04, pp. 49-50+54, 2019.

[4] Jian Zhang, Research on Dynamic Adjustment Behavior of Capital Structure and Its Influencing Factors, Time Financial, vol.07, pp. 68-69+72, 2019.

[5] Qingxia Hao, Optimization Analysis of Enterprise Capital Structure, Accountant, vol.02, pp. 3334, 2019. 